\title{
The Social And Financial Benefits Of Developing Employee Satisfaction
}

\author{
Murad Abel, Ashford University, USA
}

\begin{abstract}
Organizations continually seek to create greater efficiencies, employee engagement and organizational development opportunities. Increasing employee satisfaction allows for reduced labor costs and increase efficiencies. Satisfied employees use multiple paths of information to determine their interests in engagement which range from employer-employee relationships to compensation. The more satisfied employees are the more likely organizations will be able to capitalize on intellectual capital to navigate environmental challenges while contributing to their bottom lines.
\end{abstract}

Keywords: Employee Satisfaction; Organizational Development; Management Practices; Organizational Consulting; Labor Costs; Labor Relations

\section{INTRODUCTION}

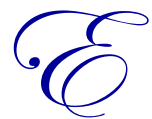

mployee satisfaction is more than the gleeful continuity of worker engagement and productivity. Satisfaction cannot be forced upon the working population with the words like "be thankful for a job" or slight employment threats of "do you like your job?" Developing the elusive concepts of employee satisfaction may be difficult but can create higher levels of organizational efficiency and return on investment if mastered well. Satisfied employees are more productive, committed, and loyal to organization needs without rigid top down management. Furthermore, such satisfied employees reward their employers with lower labor costs that can help organizations balance their budgets and improve future market prospects. Understanding the nature of employee satisfaction can create opportunities for organizational improvements that can capitalize on human abilities. As Sam Walton the founder of Wal-Mart stated "The essence of competitiveness is liberated when we make people believe that what they think and do is important - and then get out of their way while they do it".

\section{COMMITMENT AND LABOR COSTS}

Job satisfaction is based upon employee's perceptions and commitment to the work and the organizations where they are employed. When these feelings are positive, higher levels of job satisfaction often bring a number of organizational benefits. Employees, who are satisfied with their jobs, are also likely to be more committed to the organization (Miller \& Monge, 1986). This commitment manifests itself through both their workplace social networks and the employer that provides their paychecks.

It is these highly committed employees that exert the extra effort to come into work each day despite life's distractions. As employees become more involved it reduces incidents of worker withdrawal and absenteeism (Gadon, 1984). Withdrawal and absenteeism causes labor inefficiencies that can add up and damage the long term profitability of the company.

Absenteeism, grievances, and staff turnover are some signs related to a lack of employee satisfaction (McNeese-Smith, 1996). Organizations that desire to reduce these costs should consider the cultural underpinnings associated with resistance type behavior. Employers that develop corporate cultures and incentives which are designed to break down the Mauer im Kopt or Walls of the Mind also reduce miscommunication and distrust between labor and management. It is this strong communication process and trust that help to create higher levels of efficient engagement that makes it way throughout the employees daily work life. 


\section{COMPENSATION}

Employee satisfaction may also originate from a feeling of fair compensation for positive worker performance. Some may consider this an expectancy valence dynamic. Worker contributions ultimately make their way into an exchange of effort for organizational rewards (Barnard, 1938). When the rewards do not match the efforts, workers begin to feel a level of dissonance or unfairness. This feeling of unfairness will eventually increase resistance type behavior through work stoppage, absenteeism, and other costly labor reactions.

Yet compensation is not the only motivating reason why workers engage their environments. Research helps to support the idea that highly satisfied employees are willing to exert additional effort when their supervisors needed help without the immediate benefit of a reward (Berkowsitz, 1972). Workers were not oblivious to the social exchange needed to ensure organizational success. As social creatures, employees were willing to put in time and effort to overcome immediate organizational obstacles and delayed gratification for an appropriate later date.

Huseman and Hatfield believe that when employees do not earn a return on the investment in proportion to their expended energy they feel stress and anxiety (1989). This stress and anxiety can create dissonance that will lead to higher levels of distrust and disgruntled actions that reduce overall investment returns.

The conscious and subconscious choice to engage actively in their social groups and the workplace tasks relies on a number of factors. Research in Neuroeconomics helps to highlight the concept that workers make rational choices, based upon their genetic and social development, to rationally seek their own happiness (Fischman, 2012). Employees need to take a rational and willing choice to engage in the betterment of their organizations without coercion if maximum efficiencies are to be found.

Employee satisfaction is an essential element to the overall success and efficient operation of a business. As globalization encourages additional competition forms, management employers will need to find new efficiencies that do not fit easily into previous simplified mathematical models. The elusive concepts of human behavior and beliefs can continue to be defined in order to create higher levels of organizational competitiveness. In the case of employee satisfaction, it is the commitment, compensation, group norms, and leadership that can encourage organizations to reach new productive heights (see Figure 1).

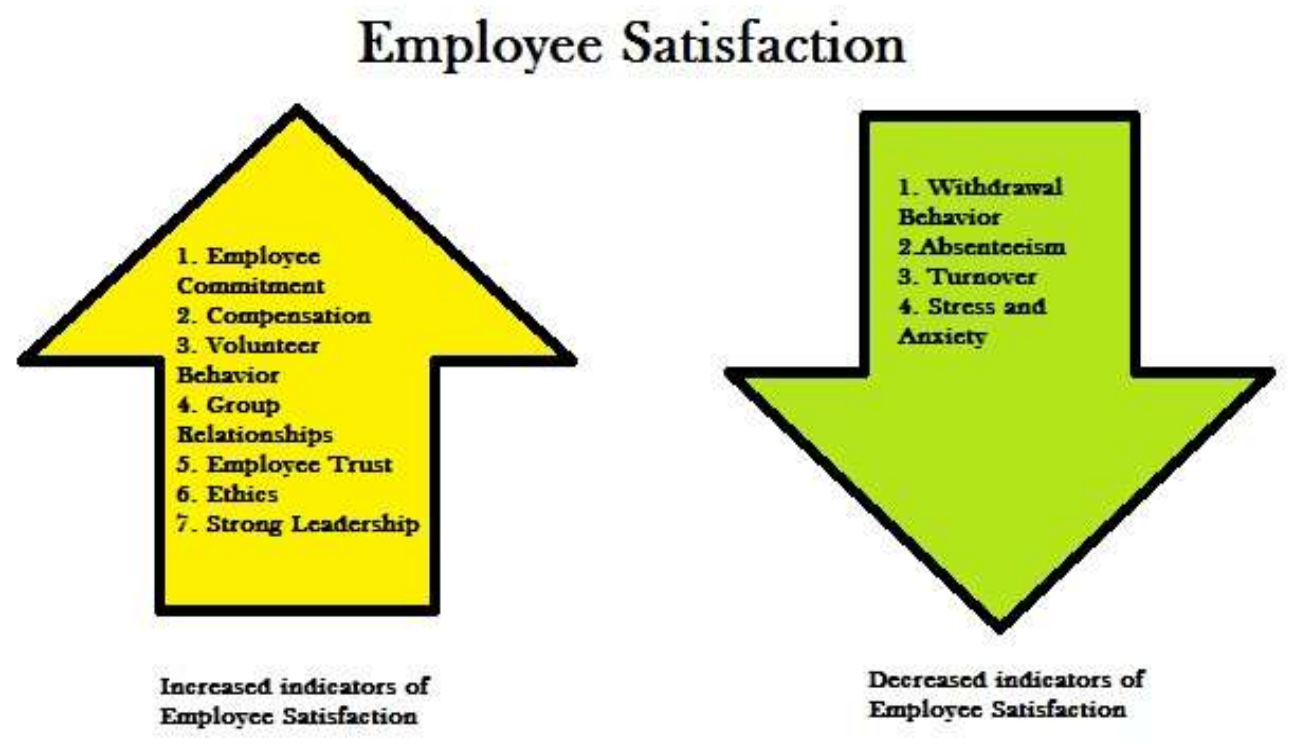

Figure 1 


\section{NORMS AND VALUES}

The system works best when there is a proper mix of norms, rewards, intrinsic satisfaction, and sentiments which are generated from group relationships (Katz, 1964). Workers seek to contribute to their organizational and social networks in ways that create a positive self-image. They often find meaning in these networks and are motivated to engage when the right mix of elements are present. The success of an organization relies heavily on the need of employees to feel part of the process and important contributors to the organizational welfare.

Such organizational citizenship behavior consists of obedience, participation, and loyalty (Graham, 1989). This type of behavior often includes moral-caring relationships that are transactional and transcend instrumental self-interest. Such relations build a sense of trust that employers and employees have mutual self-interests and similar needs based upon positive communal values.

Employees intuitively understand the rules of engagement and when they feel that this engagement is worth their effort they will show either higher levels of motivation. Much of the problems associated with engagement confusion are based in the communication process that transfers message through organizational networks. From CEO to line supervisor the messages should be consistent to ensure there is little confusion about the expectations and the pathways to success within a particular company.

Such trust and cooperation increases more significantly when reciprocated in kind by employers (Griesinger, 1990). The more social interaction and sharing of rewards the more likely employees will continue to push for higher levels of engagement and involvement. Without this trust there is little reason for ensuring both entities are having their needs fulfilled. What could be a collaborative and mutually beneficial relationship becomes a power struggle of alternative needs fulfillment.

Corporate attention to moral-ethical ideals influence self-reports of satisfaction and perceptions of altruistic and conscientious behavior of co-workers (Organ, 1977). The shared values help to create an environment where the overall value of fair play and mutual expectations abound. American businesses, in particular, rely heavily on the concepts of fair play. When there is unfair and dishonest activity in the process, the benefits of mutual self-interest begin to break down and damage the productivity of the organization.

Employee satisfaction and trust rests on an implied contract that transcends simple legal obligations. This trust factor is derived from a sense of loyalty, cooperation, and participation (Tser-Yieth, Hwang, \& Liv, 2012). The more each side engages in these trust-building behaviors the higher the trust level rises. Employers expect their workers to be loyal, cooperate in activities and participate in solutions while employees may in turn expect the employer to treat them humanely, give them opportunities for growth, and share in their needs for development.

\section{LEADERSHIP AND ROI}

Transformational leadership involves inspirational motivation, intellectual stimulation and individualized consideration behaviors when putting work into the context of employee's physical, mental, and spiritual needs (Tser-Yieth \& Shiuh-Nan, 2012). Such leadership does not only focus on the results but also on how the subtle needs of employees impact that obtainment of organizational results. The skilled transformational leader can understand and adjust these nuances for greater impact.

It is possible to view employee satisfaction in terms of the bonds and relationships that are built among leaders and employees as well as employees among each other. Relationship satisfaction and employee volunteer performances are deeply associated (Moorman, 1993). Employees naturally create groups and it is these groups that help them define who they are and what their level of expected contribution will be. Leaders have an opportunity to define the values of these groups.

There are additional benefits to employee satisfaction and engagement that move beyond the social aspects and directly into the pockets of investors. Employee engagement can increase profits and reduce expenses through satisfaction, effectiveness and motivation by creating efficiencies through engagement (Maylett \& Nielsen, 2012). 
The more employees enlist in the overall development of the organization the more efficient the company develops through the reduction in the waste in time, material and effort.

Empirical evidence is a bit elusive in such complex arrangements but does result in an imperfect association of wealth generation. For example, unstructured interviews with a sample of 21 senior managers from 16 business organizations discovered that leadership style a.) Enhanced profits through reduced turnover and organizational trust; and b.) Increased in organizations where leaders served the needs of their employees (Jones, 2012). Such leaders enhanced their organizational development and potential for profit through the creation and development positive work relationships and appropriate developmental leadership styles.

Before leadership can harness the power of employee satisfaction they need to rest on some important conclusions related to their leadership style and the latent potential of their employees. Strong leaders can empower their employees and encourage them to make their own decisions (Avolio \& Bass, 1995). It is this empowerment spread across a group of employees that creates sub-level efficiencies that are not easily measured with formal human resource approaches.

\section{CONCLUSION}

Employee satisfaction is an essential element to the overall success and efficient operation of a business. As globalization encourages additional competition forms of management employers will need to find new efficiencies that do not fit easily into previous simplified mathematical models. The elusive concepts of human behavior and beliefs can continue to be defined in order to create higher levels of organizational competitiveness. In the case of employee satisfaction it is the commitment, compensation, group norms, and leadership that can encourage organizations to reach new productive heights.

\section{AUTHOR INFORMATION}

Dr. Murad Abel works for Ashford University as a full-time instructor in human resources management, organizational development, and service management. He is researching concepts related to the overall development of viable and sustainable organizations in global markets. He seeks to develop and create new understandings to encourage American growth and development. E-mail: Murad.ali@ashford.edu

\section{REFERENCES}

1. Avolio, B. \& Bass, B. (1995). Individual consideration viewed at multiple levels of analysis: a multi level framework for examining the diffusion of transformational leadership. Leadership Quarterly, 6 (2).

2. Barnard, C. (1938). The functions of the Executive. Cambridge, MA: Harvard University Press.

3. Berkowitz, C. (1972). Social norms, feeling and other factors affecting helping behavior and altruism. In (Berkowitz (ED), Advances in Experimental Social Psychology (6, pp 63-108). New York: Academic Press.

4. $\quad$ Fischman, J. (2012, September 28th). The marketplace in your brain. The Chronicle Review.

5. Graham, J. (1989). Organizational citizenship behavior: Construct redefinition, operationalization, and validation. Unpublished paper. Department of Management, Loyola University, Chicago.

6. Griesinger, D. (1990). The human side of economic organization. Academy of Management Review, 15, 478-499.

7. Huseman, R. \& Hatfield, J. (1989). Managing the equity factor. Boston Houghton Mifflin.

8. Jones, D. (2012). Servant leadership impact on profit, employee satisfaction, and empowerment within the framework of participative culture in business. Business Studies Journal, 4 (1).

9. Katz, D. (1964). The motivational basis of organizational behavior. Behavioral Science, 9, 131-146

10. Maylett, T. \& Nielsen, J. (Apr 2012). There is no cookie-cutter approach to engagement. $T \& D, 66$ (4).

11. Moorman, R. (1993). The influence of cognitive and affective based job measures on the relationship between satisfaction and organizational citizen behavior. Human Relations, 46 (6). 759-776.

12. McNeese-Smith, D. (1996). Increasing employee productivity, job satisfaction, and organizational commitment. Hospital \& Health Services Administration, 41 (2). 
13. Miller, K. \& Monge, P. (1986). Participation, satisfaction, and productivity: A meta-analytic review. Academy of Management Journal, 29, 727-753.

14. Organ, D. (1977). Organizational citizenship behavior: The good soldier syndrome. Lexington, MA: Lexington Books.

15. Tser-Yieth, C. Hwang, S. \& Liv, Y. (2012). Antecedents of the voluntary performance of employees: clarifying the roles of employee satisfaction and trust. Public Personnel Management, 41 (3). 


\section{$\underline{\text { NOTES }}$}

